Carmen Ricós*, Pilar Fernández-Calle, Elisabet Gonzalez-Lao, Margarida Simón, Jorge Díaz-Garzón, Beatriz Boned, Fernando Marqués-García, Joana Minchinela, Maria Carmen Perich, Xavier Tejedor-Ganduxé, Zoraida Corte, Aasne K. Aarsand, Berna Aslan, Anna Carobene, Abdurrahman Coskun and Sverre Sandberg

\title{
Critical appraisal and meta-analysis of biological variation studies on glycosylated albumin, glucose and $\mathrm{HbA}_{1 c}$
}

https://doi.org/10.1515/almed-2020-0029

Received March 25, 2020; accepted April 15, 2020; published online May 19, 2020

\begin{abstract}
Objectives: Numerous biological variation (BV) studies have been performed over the years, but the quality of these studies vary. The objectives of this study were to perform a systematic review and critical appraisal of BV studies on glycosylated albumin and to deliver updated BV estimates for glucose and $\mathrm{HbA}_{1 \mathrm{c}}$, including recently published high-quality studies such as the European Biological Variation study (EuBIVAS).

Methods: Systematic literature searches were performed to identify BV studies. Nine publications not included in a
\end{abstract}

Correction notes: Correction added after online publication July 15 , 2020: In a previous version of this article, the given and family names of each author was inverted.

*Corresponding author: Carmen Ricós, Spanish Society of Laboratory Medicine (SEQC ${ }^{\mathrm{ML}}$ ), Analytical Quality Commission, Barcelona, Spain; Padilla, 323, Barcelona 08035, Spain,

E-mail: cricosaguila@gmail.com

Pilar Fernández-Calle and Jorge Díaz-Garzón: SEQC ${ }^{\mathrm{ML}}$, Analytical Quality Commission, Barcelona, Spain; EFLM, Task Group on Biological Variation Database; EFLM, Working Group on Biological Variation; and Hospital Universitario La Paz, Madrid, Spain

Elisabet Gonzalez-Lao: SEQC ${ }^{\mathrm{ML}}$, Analytical Quality Commission, Barcelona, Spain; EFLM, Task Group on Biological Variation Database; and Quality Healthcare, Grupo ACMS, Madrid, Spain

Margarida Simón: SEQC ${ }^{\mathrm{ML}}$, Analytical Quality Commission, Barcelona, Spain; EFLM, Task Group on Biological Variation Database; and Consortium of Laboratory Intercomarcal Alt Penedès and Garraf l'Anoia, Vilafranca del Penedes, Spain

Beatriz Boned: SEQC ${ }^{\mathrm{ML}}$, Analytical Quality Commission, Barcelona, Spain; EFLM, Task Group on Biological Variation Database; and Hospital Royo Villanova, Zaragoza, Spain

Fernando Marqués-García: SEQC ${ }^{\mathrm{ML}}$, Analytical Quality Commission, Barcelona, Spain; EFLM, Task Group on Biological Variation Database; and Hospital Universitario de Salamanca, Salamanca, Spain Joana Minchinela: SEQC ${ }^{\mathrm{ML}}$, Analytical Quality Commission, Barcelona, Spain; EFLM, Task Group on Biological Variation Database; and Hospital Germans Trias i Pujol, Badalona, Spain previous review were identified; four for glycosylated albumin, three for glucose, and three for $\mathrm{HbA}_{1 \mathrm{c}}$. Relevant studies were appraised by the Biological Variation Data Critical Appraisal Checklist (BIVAC). Global BV estimates were derived by meta-analysis of BIVAC-compliant studies in healthy subjects with similar study design.

Results: One study received BIVAC grade A, 2B, and 6C. In most cases, the $\mathrm{C}$-grade was associated with deficiencies in statistical analysis. BV estimates for glycosylated albumin were: $\mathrm{CV}_{\mathrm{I}}=1.4 \%(1.2-2.1)$ and $\mathrm{CV}_{\mathrm{G}}=5.7 \%$ (4.710.6), whereas estimates for $\mathrm{HbA}_{1 \mathrm{c}}, \mathrm{CV}_{\mathrm{I}}=1.2 \%(0.3-2.5)$, $\mathrm{CV}_{\mathrm{G}}=5.4 \%$ (3.3-7.3), and glucose, $\mathrm{CV}_{\mathrm{I}}=5.0 \%$ (4.1-12.0), $\mathrm{CV}_{\mathrm{G}}=8.1 \%$ (2.7-10.8) did not differ from previously published global estimates.

Maria Carmen Perich: SEQC ${ }^{\mathrm{ML}}$, Analytical Quality Commission, Barcelona, Spain; EFLM, Task Group on Biological Variation Database; and Hospital Vall d'Hebron, Barcelona, Spain Xavier Tejedor-Ganduxé: SEQC ${ }^{\mathrm{ML}}$, Analytical Quality Commission, Barcelona, Spain; EFLM, Task Group on Biological Variation Database; and Hospital Germans Trias i Pujol, Badalona, Spain

Zoraida Corte: SEQC ${ }^{\mathrm{ML}}$, Analytical Quality Commission, Barcelona, Spain; Hospital Universitario San Agustin, Aviles, Spain

Aasne K. Aarsand: EFLM, Task Group on Biological Variation Database; EFLM, Working Group on Biological Variation; Haukeland University Hospital, Bergen, Norway; and Norwegian Quality Improvement of Laboratory Examinations, Haraldplass Deaconess Hospital, Bergen, Norway

Berna Aslan: EFLM, Task Group on Biological Variation Database; Institute for Quality Management in Healthcare of Canada, Toronto, Canada

Anna Carobene: EFLM, Task Group on Biological Variation Database; EFLM, Working Group on Biological Variation; and Laboratory Medicine, Ospedale San Raffaele, Milan, Italy

Abdurrahman Coskun: EFLM, Task Group on Biological Variation Database; EFLM, Working Group on Biological Variation; and Acibadem Universitesi, Istanbul, Turkey

Sverre Sandberg: EFLM, Task Group on Biological Variation Database; EFLM, Working Group on Biological Variation; and Department of Global Public Health and Primary Care, University of Bergen, Bergen, Norway

This work is licensed under the Creative Commons Attribution 4.0 
Conclusions: The critical appraisal and rating of BV studies according to their methodological quality, followed by a meta-analysis, generate robust, and reliable BV estimates. This study delivers updated and evidence-based BV estimates for glycosylated albumin, glucose and $\mathrm{HbA}_{1 \mathrm{c}}$.

Keywords: biological variation; biological variation critical appraisal checklist; biological variation database; diabetes mellitus.

\section{Introduction}

Biological variation (BV) is defined as the random fluctuation of a measurand in a biological fluid to achieve a balance between turnover and the homeostatic setting point [1-3]. BV has two components: within-subject and betweensubject variation, which may be expressed as variation coefficients $\left(\mathrm{CV}_{\mathrm{I}}\right.$ and $\mathrm{CV}_{\mathrm{G}}$, respectively) [4]. In 1998, Fraser and Harris published a BV estimation model that has been widely used [1]. In 1999, the SEQC ${ }^{\mathrm{ML}}$ Analytical Quality Commission [5, 6] compiled all publications containing BV estimates in a database that was updated every two years until 2014 [7]. The inclusion criteria employed have been extensively described by Perich et al. [8].

Despite the credibility and widespread use of the database created by Ricós et al., a number of authors have raised concerns about the accuracy and relevance of some of the BV estimates published in this database [9-11]. In response to this, the European Federation of Clinical Chemistry and Laboratory Medicine (EFLM) Working Group on Biological Variation (WG-BV) and the Task Group for the Biological Variation Database (TG-BVD) have undertaken several initiatives to improve the quality of available BV data, including developing a critical appraisal checklist to be applied to studies on BV, the Biological Variation Data Critical Appraisal Checklist (BIVAC) [12]. Applying this quality appraisal tool, the groups have been reviewing and critically appraising $\mathrm{BV}$ studies for a wide range of measurands and developed a meta-analysis approach to produce global BV estimates. The results of the critical reviews and meta-analysis derived global estimates for measurands associated with diabetes mellitus (DM) [13], lipids [14], and hematologic parameters [15] have recently been published.

Furthermore, the results of this systematic appraisal of $\mathrm{BV}$ data are being made publically available in the EFLM Biological Variation Database (EFLM BVD) [16]. This database was launched in the 23rd European Congress of Clinical Chemistry and Laboratory Medicine, EuroMedlab 2019 and is available at https://biologicalvariation.eu/ [16]. Presently, global BV estimates derived from meta-analysis have been published for more than 100 measurands and data are continuously being added. Thus, the new database provides quality-assured and updated data on the measurands most commonly tested in clinical laboratories for the management and monitoring of high-prevalence diseases.

One of the most prevalent diseases in the world is DM (8.5\%) [17]. Accordingly, a wide range of international guidelines and recommendations have been published for the diagnosis and monitoring of glycemia. Glycosylated albumin has, for the last years, been attracting increasing attention of the scientific community [18-20] as an indicator of intermediate metabolism of glucose in settings that may interfere with the metabolism of hemoglobin.

Numerous papers on BV studies of diabetes-related measurands have been published over the last decade and our group has previously performed a systematic review and critical appraisal of BV studies for diabetes-related measurands, published in 2019 [13]. However, glycosylated albumin was not included in this systematic review as only one article had been published on this measurand to that date. Furthermore, high-quality studies such as the European Biological Variation Study (EuBIVAS) [21], a multicenter large-scale BV study was at the time of the previous review not yet published and thus not included. The objectives of this study were thus to perform a systematic review and critical appraisal for BV studies for glycosylated albumin and to deliver updated BV estimates for glucose and $\mathrm{HbA}_{1 \mathrm{c}}$, including recently published high-quality studies such as the EuBIVAS [21].

\section{Materials and methods}

A systematic literature review and critical appraisal of BV studies were conducted for glycosylated albumin, glucose and $\mathrm{HbA}_{1 \mathrm{c}}$. A non time limited search for glycosylated albumin and furthermore, whereas for glucose and $\mathrm{HbA}_{1 \mathrm{c}}$ a complementary search was conducted only for the period from June 2018 and December 2019 (studies published after first review), using the same keywords and terms as in the previous review [13]. The search for studies related to glycosylated albumin was performed in the same manner, but without any time limit.

The BIVAC [12] is composed of 14 quality items and grades BV studies as A, B, C, and D in decreasing order of quality according to the level of compliance with each quality item. Quality item 1 assesses the scale of the measurand. Quality items 2-4 assess whether the characteristics of the subjects, samples, and measurement methods employed are described in sufficient detail, respectively. Quality items five to seven focus on pre-analytical and analytical conditions and whether steady state of participants has been assessed or data adequately transformed. Quality items 8-12 assess the measurement methods and statistical procedures used to derive $C_{\mathrm{I}}$ and $\mathrm{CV}_{\mathrm{G}}$ estimates. Quality items 13-14 refer to whether the number of results included in BV calculations and measurand concentrations are reported or not, respectively. 
BV studies are graded as a function of the minimum score obtained for any of the quality items. A study showing full compliance with the 14 quality items is graded as " $A$ ". If essential requirements defined for quality items 2 , three and four are not complied with, the study will be rated as " $\mathrm{D}$ ".

Overall $\mathrm{CV}_{\mathrm{I}}$ and $\mathrm{CV}_{\mathrm{G}}$ estimates were derived from meta-analysis [22] of studies with similar study design performed in healthy adult individuals, by a weighted median approach. The BIVAC quality grades were used as weight, $(\mathrm{A}=4, \mathrm{~B}=2 ; \mathrm{C}=1)$ together with inverse width of $95 \%$ confidence intervals (CI) of the $\mathrm{CV}_{\mathrm{I}}$ and $\mathrm{CV}_{\mathrm{G}}$ values obtained in each study. The $95 \%$ confidence intervals (95\% CI) for the global estimates were calculated by the bias-corrected bootstrap method [23].

As described above, a meta-analysis was conducted to calculate the global BV estimates for each measurand. In the meta-analysis, all relevant studies fulfilling the inclusion criteria were included, i. e., both those identified in the previous review and those published after this review was finalized. The meta-analysis only included BV studies with a BIVAC grade $\mathrm{A}-\mathrm{C}$, based on a sample of more than three healthy adults (18-75 years of age) from whom more than three samples had been taken per subject at a once-a-month to twice-a-week sampling interval. For inclusion, studies were also required to describe BV results in detail and report estimates of analytical coefficients of variation $\left(\mathrm{CV}_{\mathrm{A}}\right)$. When stratified and overall $\mathrm{BV}$ data were provided in a publication (by age or sex, among other), only overall data were considered for the calculation of estimates to avoid duplicity of data.

\section{Results}

The literature search identified six articles, dealing with healthy subjects. Of these only two were published after the BIVAC [12] (between March 2018 and December 2019) and four reported BV results for glycosylated albumin. Table 1 provides an overview of the appraised articles and for which measurands they have reported data.

Table 2 shows the number of articles which have been reviewed and their BIVAC grade. Glucose was the measurand with the highest number of publications. For the majority of studies, a BIVAC C grade was awarded (Table 2). Table 3 contains the overall $\mathrm{CV}_{\mathrm{I}}$ and $\mathrm{CV}_{\mathrm{G}}$ estimates derived by meta-analysis including all relevant studies.

Figure 1 shows the reported $\mathrm{CV}_{\mathrm{I}}$ estimates of glycosylated albumin, a measurand that was not included in the previous review [13]. Notably, $\mathrm{CV}_{\mathrm{G}}$ estimates were only reported in three papers, with the most recent study reporting lower values than previous studies, as follows: $\mathrm{CV}_{\mathrm{G}}=4.7 \mathrm{vs}$. $10.3 \%$ and $10.7 \%$.

\section{Discussion}

The clinical relevance of the measurands used for the diagnosis and monitoring of DM makes it necessary that BV estimates for these measurands are robust and reliable. BV data are also used to produce analytical imprecision and bias specifications, which are essential for an optimal laboratory performance. In addition, reference change values are calculated based on $\mathrm{BV}$, which enables an appropriate interpretation of serial results [2, 3, 24].

Although glucose and $\mathrm{HbA}_{1 \mathrm{c}}$ traditionally have been used for the diagnosis and monitoring of glycemia, some

Table 1: Papers revised in this study.

\begin{tabular}{|c|c|c|c|}
\hline Year & Paper & Analyte & n \\
\hline 2019 & $\begin{array}{l}\text { Liang L, He H, Zeng Y, Zhang M, } \\
\text { Wang X, Li X, Liang S et al. } \\
\text { Evaluation of biological varia- } \\
\text { tion of glycated hemoglobin } \\
\text { and glycated albumin in } \\
\text { healthy Chinese subjects. J Clin } \\
\text { Lab Anal } 2019 ; 33: 322,715 \text {. } \\
\text { https://doi.org/10.1002/jcla. } \\
2275 .\end{array}$ & $\begin{array}{l}\text { Glycosylated al- } \\
\text { bumin } \mathrm{HbA}_{1 \mathrm{C}}\end{array}$ & 501 \\
\hline 2018 & $\begin{array}{l}\text { Aarsand AK, Diaz-Garzón J, Fer- } \\
\text { nandez-Calle P, Guerra E, } \\
\text { Locatelli M, Bartlett WA et al. } \\
\text { The EuBIVAS: Within- and be- } \\
\text { tween-subject biological varia- } \\
\text { tion data for electrolytes, lipids, } \\
\text { urea, uric acid, total protein, } \\
\text { total bilirubin, direct bilirubin, } \\
\text { and glucose. Clin Chem } \\
\text { 2018;64:1380-1393. }\end{array}$ & Glucose & 335 \\
\hline 2015 & $\begin{array}{l}\text { Parrinello CM, Lutsey PL, Couper } \\
\text { D, Eckfeldt JH, Steffes MW, } \\
\text { Caresh J et al. Total short-term } \\
\text { variability in biomarkers of hy- } \\
\text { perglycemia in older adults. } \\
\text { Clin Chem 2015;61:1540-1548 }\end{array}$ & $\begin{array}{l}\text { Glycosylated al- } \\
\text { bumin }\end{array}$ & 278 \\
\hline 2013 & $\begin{array}{l}\text { Montagnana M, Paleari R, Danese } \\
\text { E, Salvagno GL, Lippi G, Giuidi } \\
\text { GC et al. Evaluation of biolog- } \\
\text { ical variation of glycated albu- } \\
\text { min (GA) and fructosamine in } \\
\text { healthy subjects. Clin Chim } \\
\text { Acta } 2013 ; 423: 1-4\end{array}$ & $\begin{array}{l}\text { Glycosylated al- } \\
\text { bumin }\end{array}$ & 273 \\
\hline 2012 & $\begin{array}{l}\text { Xue L, Liang } \mathrm{H} \text {, Jiang } \mathrm{X} \text {. Circanual } \\
\text { temperature-related variation } \\
\text { in } \mathrm{HbA}_{1 \mathrm{c}} \text { is unlikely to affect its } \\
\text { use as a diagnostic test for type } \\
2 \text { Diabetes. Clin Lab } \\
\text { 2012;58:481-488 [29]. }\end{array}$ & Glucose & 307 \\
\hline 1993 & $\begin{array}{l}\text { Davie SJ, Whiting KL, Gould } \\
\text { BJ. Biological variation in gly- } \\
\text { cated proteins. Ann Clin Bio- } \\
\text { chem 1993;30:260-264 }\end{array}$ & $\begin{array}{l}\text { Glycosylated al- } \\
\text { bumin }\end{array}$ & 31 \\
\hline
\end{tabular}


authors advocate the use of glycosylated albumin for the diagnosis, prevention, and monitoring of diabetes in diabetic patients in clinical settings that may interfere with hemoglobin metabolism [18-20]. Hence, the relevance of providing robust $\mathrm{BV}$ estimates to laboratories using this monitoring strategy.

As in the previous systematic review, appraisal by the BIVAC demonstrates that the majority of studies published for diabetes-related measurands have similar methodological weaknesses [13]. Summarizing all the 75 studies (first and present reviews) most were graded as "C" regardless of the measurand addressed for the following reasons: outliers

Table 2: Number of articles reviewed and BIVAC grade for publications reporting $\mathrm{BV}$ estimates for DM related measurands.

\begin{tabular}{lccccr}
\hline & & \multicolumn{4}{c}{ BIVAC grade } \\
\cline { 3 - 6 } Measurand & n & A & B & C & D \\
\hline Glycosylated albumin & 4 & 0 & 1 & 3 & 0 \\
$\mathrm{HbA}_{1 \mathrm{c}}$ & 3 & 0 & 1 & 1 & 1 \\
Glucose $_{\text {Previous systematic revision }}[13]$ & 1 & 0 & 6 & 0 \\
Glycosylated albumin & NA & NA & NA & NA & NA \\
HbA $_{1 \mathrm{c}}$ & 17 & 1 & 2 & 10 & 4 \\
Glucose & 23 & 2 & 1 & 20 & 0 \\
\hline
\end{tabular}

$\mathrm{n}$, number of articles reviewed; NA, not assessed.

Table 3: Overall estimates for BV components.

\begin{tabular}{lll}
\hline Measurand & $\mathrm{CV}_{\mathbf{1}} \%(\mathbf{9 5 \%} \mathrm{Cl})$ & $\mathrm{CV}_{\mathbf{G}} \%(\mathbf{9 5 \%} \mathrm{Cl})$ \\
\hline Glycosylated albumin & $1.4(1.2-2.1)$ & $5.7(4.7-10.6)$ \\
$\mathrm{HbA}_{1 \mathrm{c}}$ & $1.2(0.3-2.5)$ & $5.4(3.3-7.3)$ \\
Glucose & $5.0(4.1-12.0)$ & $8.1(2.7-10.8)$ \\
\hline
\end{tabular}

$\mathrm{CV}_{1}$, within-subject biological variation. $\mathrm{CV}_{1}$, between-subject biological variation. $95 \% \mathrm{Cl}, 95 \%$ confidence interval.

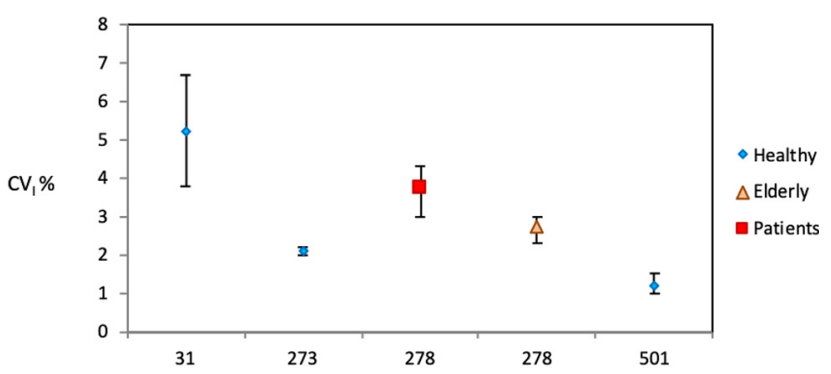

Figure 1: Glycosylated albumin.

$\mathrm{CV}_{1}$ and their confidence intervals for the four papers included in this review. $X$ axis: paper ID number, according to Table 1. were not identified and removed (quality item 8) in 86\%; homogeneity of variance had not been assessed in $64 \%$ (item 10). In $50 \%$, CI for BV estimates were not reported, could not be calculated, or the number of results excluded were not documented (quality items 12 and 13 , respectively); $\mathrm{CV}_{\mathrm{A}}$ estimates were calculated based on internal quality control instead of replicate analyses of samples in 60 and $30 \%$ of the papers included in the first and the second review, respectively (quality item 6); steady state of the patient during the study period was not assessed in $20 \%$ (quality item 7 ).

The methodological flaws of studies may affect the reliability of the resulting estimates. Failure to identify outliers (quality item eight of BIVAC) and assess the homogeneity of variance (quality item 10 ), may cause $\mathrm{CV}_{\mathrm{I}}$ and $\mathrm{CV}_{\mathrm{G}}$ estimates not to be generalizable or reliable.

The lack of data on the total number of results used to calculate BV estimates (quality item 13) in many studies makes it difficult to assess group homogeneity and the generalizability and reliability of the estimates.

A BIVAC grade A requires that BV studies estimate $\mathrm{CV}_{\mathrm{A}}$ by replicate analysis of study samples (quality item 6) $[1,12]$.

Another relevant aspect is assessing the steady state of subjects during the study period (quality item 7), since variations in concentrations may result in inaccurate $\mathrm{CV}_{\mathrm{I}}$ and $\mathrm{CV}_{\mathrm{G}}$ estimates.

One of the strengths of BIVAC is that the meta-analysis model employed to produce a final $\mathrm{CV}_{\mathrm{I}}$ and $\mathrm{CV}_{\mathrm{G}}$ estimate gives priority and more weight to $\mathrm{BV}$ data derived from BIVAC compliant studies.

For glucose, two new articles which fulfilled the inclusion criteria were identified in this review. These were included in the meta-analysis to provide the updated estimates. However, the updated estimates did not differ from those published in the previous review (Table 2).

For $\mathrm{HbA}_{1 \mathrm{c}}$, the $\mathrm{CV}_{\mathrm{I}}$ and $\mathrm{CV}_{\mathrm{G}}$ estimates were also similar to those reported in the previous review [13], with a narrower $\mathrm{CI}$ that may be explained by the inclusion of a highquality study graded as B [25] (number 501 in Table 1).

A considerable dispersion of the $\mathrm{CV}_{\mathrm{I}}$ values reported for glycosylated albumin in the four studies conducted in healthy adults was observed, with the two most recent studies (numbers 273 [26] and 501 [25], from 2013 to 2019, respectively) reporting lower $\mathrm{CV}_{\mathrm{I}}$ values (Figure 1). Three articles were included in the meta-analysis, whereas one ([27] number 31) was excluded as $\mathrm{CV}_{\mathrm{A}}$ values were not reported and CIs could not be calculated. Significantly higher estimates were documented in a study in subjects older than 75 and in a study in diabetic subjects [28] (number 278 in Figure 1). 
The high $\mathrm{CV}_{\mathrm{I}}$ obtained in the earliest paper [27] (number 31 in Figure 1) from 1993) can be explained by the use of an outdated analytical method (affinity chromatography), as compared to the other articles, where more specific analysis (automated enzymatic), was used. A study [25] involving Chinese population reports a lower $\mathrm{CV}_{\mathrm{I}}$ estimate, which might be explained by ethnicity-based differences.

These estimates $\mathrm{CV}_{\mathrm{I}}=1.4 \%(1.2-2.1), \mathrm{CV}_{\mathrm{G}}=5.7 \%$ (4.7-10.6) differ remarkably from those contained in the 2014 database [7] $\left(\mathrm{CV}_{\mathrm{I}}=5.2 \%\right.$ and $\left.\mathrm{CV}_{\mathrm{G}}=10 \%\right)$, as only data from the study based on affinity chromatography were included in the former database. Further high-quality studies are required to produce reliable $\mathrm{CV}_{\mathrm{I}}$ and $\mathrm{CV}_{\mathrm{G}}$ estimates for glycated albumin.

The BIVAC was published in March 2018. Only two studies were identified in this review that was published after the BIVAC became publically available. These two papers, one study on glucose and one glycosylated albumin and $\mathrm{HbA}_{1 \mathrm{C}}$, were graded as $\mathrm{A}$ [21] (number 335 in Table 1) and B [25] (number 501 in Table 1), respectively, which may indicate that the authors followed the BIVAC to assist in their BV study design and analysis. However, one of these studies is the EuBIVAS, which is published by the WG-BV, who have followed this design consistently also prior to the BIVAC. Therefore, though one of the aims of the BIVAC is to improve in the quality in future studies; it is too early to draw any conclusions on this].

\section{Conclusions}

The application of the BIVAC to evaluate the quality of BV studies is a standardized method that aids in the production of robust and reliable BV estimates. In our study, we have delivered global BV estimates for glycated albumin based on critical appraisal and meta-analysis of relevant studies. The inclusion of recently published studies for glucose and $\mathrm{HbA}_{1 \mathrm{c}}$ did not significantly impact the point estimate delivered by our previous review. However, the future inclusion of a higher proportion of high-quality studies may have a greater impact and is likely to progressively decrease the width of the CI.

The impact of BIVAC is not restricted to the appraisal of publications, but it also provides an international standard for the design, performance, and publication of BV studies, and provides standard guidelines for the design of new BV studies.

The scarcity of studies receiving the highest BIVAC grade demonstrates the need for more fully BIVACcompliant studies to provide robust BV estimates. The use of the BIVAC for the design and development of studies may be instrumental to improve the quality and reliability of BV estimates in the future.
Acknowledgments: The authors thanks to Roche Diagnostics and Siemens Healthineers for sponsoring meeting of the EFLM groups. Also thank to the Spanish Society of Laboratory Medicine (SEQC ${ }^{\mathrm{ML}}$ ) for holding our face to face meeting in its Barcelona office.

Research funding: Siemens Healthineers and Bio Rad Laboratories for facilitating the authors' meetings.

Author contributions: All authors have accepted responsibility for the entire content of this manuscript and approved its submission.

Competing interests: Authors state no conflict of interest. Ethical approval: Not applicable.

\section{References}

1. Fraser CG, Harris EK. Generation and application of data on biological variation in clinical chemistry. Crit Rev Clin Lab Sci 1989;27:409-37.

2. Fraser CG. Biological variation: from principles to practice. Washington, DC: AACC Press; 2001

3. Fraser CG. Variación Biológica: de la teoría a la práctica. Traducción de la Sociedad Española de Bioquímica Clinica and Patologia Molecular. 1st ed. Barcelona; 2003.

4. Simundic AM, Kackov S, Miler M, Fraser CG, Petersen PH. Terms and symbols used in studies on biological variation: the need for harmonization. Clin Chem 2015;61:438-9.

5. Ricós C, Alvarez V, Cava F, García-Lario JV, Hernández A, Jiménez CV, et al. Current database on biological variation: pos, cons and progress. Scand J Clin Lab Invest 1999;59:491-500.

6. Traducción española en: Estrategias para establecer especificaciones globales de la calidad analítica en el laboratorio clínico. Barcelona: Monografía SEQC; 2000.

7. Minchinela J, Ricós C, Perich C, Férnandez-Calle P, Álvarez V, Domenech $\mathrm{M}$, et al. Biological variation database, and quality specifications for imprecision, bias and total error (desirable and minimum); The 2014 update. Available from: https://www.westgard.com/biodatabase1.htm [Acceso Marzo 2019].

8. Perich C, Michinela J, Ricós C, Fernandez-Calle C, Álvarez V, Domenech MV, et al. Biological variation database: structure and criteria used for generation and update. Clin Chem Lab Med 2015; 53:299-305.

9. Aarsand A, Røraas T, Sandberg S. Biological variation: reliable data are essential. Clin Chem Lab Med 2015;53:153-4.

10. Carobene A. Reliability of biological variation data available in an online database: need for improvement. Clin Chem Lab Med 2015; 53:871-7.

11. Carobene A, Braga F, Roraas T, Sandberg S, Bartlett WA. A systematic review of data on biological variation for alanine aminotransferase, aspartate aminotransferase and $\gamma$-glutamyl transferase. Clin Chem Lab Med 2013;51:1997-2007.

12. Aarsand A, Roraas T, Fernández-Calle P, Ricós C, Diaz-Garzón J, Jonker N, et al. On behalf of the EFLM Working Group on Biological Variation and Task and Finish Group for the Biological Variation Database. The biological variation data critical appraisal checklist (BIVAC): a new standard for evaluating studies on biological variation. Clin Chem 2018;64:501-4. 
13. González-Lao E, Corte Z, Simón M, Ricós C, Coskun A, Braga F, et al. Systematic review of the biological variation data for diabetes related measurands. Clin Chim Acta 2019;488:61-7.

14. Díaz-Garzón J, Fernández-Calle P, Minchinela P, Aarsand AK, Bartlett W, Aslan B, et al. Biological variation data for cardiovascular risk assessment biomarkers. A systematic review using the critical appraisal checklist (BIVAC). Clin Chim Acta 2019;495:467-75.

15. Coskun A, Braga F, Carobene A, Tejedor X, Aarsand A, FernándezCalle $P$, et al. Systematic review and meta-analysis of withinsubject and between-subject biological variation estimates of haematological parameters. ClinChem Lab Med 2019;58:25-32.

16. Aarsand AK, Fernandez-Calle P, Webster C, Coskun A, Gonzalez-Lao E, Diaz-Garzón J, et al. The EFLM biological variation database. Available from: https:// biologicalvariation.eu/ [Accesed 22 Mar 2020].

17. WHO. Global report on diabetes. Available from: https://www. who.int/diabetes/global-report/en/ [Accessed 0201 2020].

18. Freitas PAC, Ehlert LR, Camargo JL. Glycated albumin: a potential biomarker in diabetes. Arch Endocrinol Metab 2017;61:296-304.

19. Gan T, Liao B, Xu G. The clinical usefulness of glycated albumin in patients with diabetes and chronic kidney disease : progress and challenges. J Diabetes Complications 2018;32:876-84.

20. Clemens KK, O'Rean N, Rhee JJ. Diabetes management in older adults with chronic kidney disease. Curr Diab Rep 2019;19:11.

21. Aarsand AK, Diaz-Garzón J, Fernandez-Calle P, Guerra E, Locatelli $M$, Bartlett WA, et al. The EuBIVAS: within- and between-subject biological variation data for electrolytes, lipids, urea, uric acid, total protein, total bilirubin, direct bilirubin, and glucose. Clin Chem 2018;64:1380-93.
22. Røraas T, Petersen P, Sandverg S. Confident intervals and power calculations for within-person biological variation: effect of analytical imprecision, number of replicates, number of samples, and number of individuals. Clin Chem 2012;58: 1306-13.

23. Tu D, Shao J. The jackknife and bootstrap. 1st ed. NewYork, NY: Springer Series in Statistics; 1995.

24. Ricós C, Iglesias N, García-Lario JV, Simón M, et al. Within-subject biological variation in disease: collated data and clinical consequences. Ann Clin Biochem 2007;44:343-52.

25. Liang L, He H, Zeng Y, Zhang M, Wang X, Li X, Liang S, et al. Evaluation of biological variation of glycated hemoglobin and glycated albumin in healthy Chinese subjects. J Clin Lab Anal 2019;33:e22715.

26. Montagnana M, Paleari R, Danese E, Salvagno GL, Lippi G, Giuidi $\mathrm{GC}$, et al. Evaluation of biological variation of glycated albumin (GA) and fructosamine in healthy subjects. Clin Chim Acta 2013; 423:1-4.

27. Davie SJ, Whiting KL, Gould BJ. Biological variation in glycated proteins. Ann Clin Biochem 1993;30:260-4.

28. Parrinello CM, Lutsey PL, Couper D, Eckfeldt JH, Steffes MW, Caresh J, et al. Total short-term variability in biomarkers of hyperglycemia in older adults. Clin Chem 2015;61:1540-8.

29. Xue L, Liang H, Jiang X. Circanual temperature-related variation in HbA1c is unlikely to affect its use as a diagnostic test for type 2 Diabetes. Clin Lab 2012;58:481-8.

Article Note: A translation of this article can be found here: https:// doi.org/10.1515/almed-2020-0040 